\title{
Interannual variability and correlation of vegetation cover and precipitation in Eastern China
}

\author{
Dejuan Jiang $\cdot$ Hua Zhang $\cdot$ Yong Zhang $\cdot$ Kun Wang
}

Received: 24 October 2012 / Accepted: 18 November 2013 / Published online: 29 November 2013

(C) Springer-Verlag Wien 2013

\begin{abstract}
Based on the SPOT/VEGETATION Normalized Difference Vegetation Index (NDVI) data and daily precipitation data of 357 meteorological stations, the spatial and temporal variability of vegetation cover, measured by NDVI, and precipitation as well as their relationships are investigated in Eastern China, which is portioned into three subregions (regions I, II, and III), for the period 1998-2010. The results show that high NDVI values appear mainly in Northeastern China and in August while high precipitation (PRETOT) occurs in Southeastern China and in July (June for Southern China). Extreme precipitation days (RD95p) and amount (EPRETOT) coincide well with PRETOT. Extreme precipitation intensity (RINTEN) has a similar spatial variability to PRETOT but with a smaller seasonal variation than PRETOT. Growing season NDVI is positively correlated with PRETOT in $11.7 \%$ of the study area (mostly in arid to subhumid regions of Northern China), where precipitation is a limiting factor for vegetation growth. In contrast, a negative correlation between growing season NDVI and PRETOT is found in $4.8 \%$ of the study area, mostly in areas around the Yangtze River and deep Northeastern China. No significant correlations between these two variables are found for the other regions because
\end{abstract}

\section{Jiang $(\bowtie) \cdot H$. Zhang}

Key Laboratory of Coastal Environmental Processes and

Ecological Remediation, Yantai Institute of Coastal Zone Research,

Chinese Academy of Sciences, Yantai, Shandong 264003,

People's Republic of China

e-mail: djjiang@yic.ac.cn

Y. Zhang

Shandong Provincial Land Surveying and Planning Institute,

Jinan 250014, China

K. Wang

State Key Laboratory of Remote Sensing Science, Jointly Sponsored by the Institute of Remote Sensing and Digital Earth of Chinese Academy of Sciences and Beijing Normal University,

Beijing 100101, China vegetation response to precipitation is affected by other factors such as temperature, radiation, and human disturbance. On a monthly scale, there is a positive correlation between NDVI and PRETOT in May (for region II) and September (all subregions except region I). NDVI variations lag 1 month behind PRETOT in June (for region I) and October. Correlations between NDVI and RD95p, EPRETOT are similar to that with PRETOT, but the relationships between NDVI and RINTEN are relatively weaker than with PRETOT. This study provides the technical basis for agriculture development and ecological construction in Eastern China.

\section{Introduction}

Climate variability has a large impact on terrestrial ecosystems and aboveground biomass production (Qi et al. 2000; Nemani et al. 2003; Fabricante et al. 2009; García-Romero et al. 2010). Vegetation, as an important component of terrestrial ecosystems, links pedosphere, atmosphere, and hydrosphere of the Earth's system (Salim et al. 2008; Zhong et al. 2010). Vegetation dynamics are highly associated with climate regimes (Piao et al. 2006; Fabricante et al. 2009; Meng et al. 2011), and thus, land cover can serve as an ecological indicator for environmental changes at the local, regional, and global scales (Piao et al. 2006; Yu et al. 2006; Potter et al. 2008; Salim et al. 2008; Jiang et al. 2013). Nemani et al. (2003) estimated that water availability most strongly limits vegetation growth for over $40 \%$ of Earth's vegetated surface, while temperature over $33 \%$ and radiation over $27 \%$ of Earth's vegetated surface. Changes in vegetation cover can also affect local, regional, and global climate through various physical, physiological, and chemical feedbacks (Kaufmann et al. 2003; Suzuki et al. 2007; Zhou et al. 2007; Salim et al. 2008; Zuo et al. 2011). Vegetation dynamics and their correlations with climate variables have become one of the main themes of 
global change studies (Rees et al. 2001; Yu et al. 2006; Jiang et al. 2013).

Plant growth is highly sensitive to changes in precipitation (Fabricante et al. 2009). The regional and seasonal difference of precipitation, to a certain extent, determines the vegetation pattern. Since the 1980s, a number of researchers have examined the correlations between vegetation characteristics and precipitation at regional or national scales (e.g., Roerink et al. 2003; Nezlin et al. 2005; Bates et al. 2006; Piao et al. 2006; Suzuki et al. 2007; Méndez-Barroso et al. 2009; GarcíaRomero et al. 2010; Zhong et al. 2010; Meng et al. 2011). However, few studies have documented their relationships at fine temporal and spatial scales. Very little effort has been made to investigate the response of vegetation to precipitation extremes. Yet, extreme precipitation events influence vegetation dynamics. For instance, floods, arising from heavy rainfall events, create waterlogged conditions which restrain plant growth whereas vegetation hardly grows in the extremely dry climatic conditions (Zhong et al. 2010). The detection of vegetation response to precipitation and its extremes at a small spatial and temporal scale can be helpful to understand the characteristics of vegetation dynamics and to make scientific decisions for regional agricultural development and ecological construction.

Eastern China, one of the most populated regions in the world, has been experiencing rapid industrial growth and agricultural intensification (Piao et al. 2004; Domroes and Schaefer 2008; Zhu et al. 2011). The terrain and climate vary significantly in space, with the altitude increasing from east to west, the temperature from north to south, and the rainfall from northwest to southeast. As a result, the vegetation types are diverse, consisting of forests, grasslands, meadows, swamps, and deserts. Since the Reform and Opening-up Policy of China (the year of 1978), rapid economic developments have accelerated land cover changes in Eastern China, leading to dramatic alterations in vegetation quality and quantity (Piao et al. 2004). Hence, it is important to investigate vegetation response to climate variables and human disturbance in Eastern China. The objectives of this research are twofold: (1) analyze the temporal-spatial variability of vegetation cover and precipitation in Eastern China based on remote sensing data and in situ meteorological data and (2) to correlate the vegetation changes with precipitation and its extremes.

\section{Materials and methods}

\subsection{Study area}

Eastern China (abbreviated as EC in figures and tables) covers China east of $105^{\circ} \mathrm{E}$ longitude. Taiwan, Nansha, and Dongsha Islands are excluded in the analysis for lack of meteorological data (Fig. 1). Dominated by the East Asian Monsoon, the precipitation is highly variable over time and space. The annual precipitation over the period 1961-2010 varies from 842 to $1,083 \mathrm{~mm}$, averaging $933 \mathrm{~mm}$ per year. Most of precipitation falls during the summer (June, July, and August). Precipitation is abundant and flood disasters frequently occur in Southern China. In contrast, precipitation is scanty and droughts often occur in Northern China, particularly in Northwest China. Natural plants in Eastern China include needle-leaf forest, broadleaf forest, shrubs and woodlands, grasslands and shrub-steppes, meadows and herbaceous swamps, and deserts (Fig. 2). Cultivated plants include grain crops, orchard, and economic forest. In Northern China, most natural plants are deciduous or wilted, and agricultural lands are almost clear in winter months (December, January, and February). In Northeastern China, snow on the ground from November to March makes it difficult to detect vegetation cover. Therefore, only the time period from April to October is considered in this study. For simplicity of discussion, this period is called as the growing season, though the true growing season may vary from North to South in Eastern China.

\subsection{Data and methods}

Normalized Difference Vegetation Index (NDVI) is regarded as a good vegetation indicator for its close association with other parameters such as vegetation coverage, leaf area index, photosynthesis, and net primary productivity. It has been used to monitor and quantify vegetation cover of a large and complex ecosystem (Roerink et al. 2003; Nezlin et al. 2005; Zhong et al. 2010). Satellite data, such as NOAA/AVHRR (Roerink et al. 2003; Nezlin et al. 2005; Piao et al. 2006; Fabricante et al. 2009; Meng et al. 2011), SPOT/ VEGETATION (SPOT-VGT) (Zhong et al. 2010; Cui and Shi 2010; Qiu and Cao 2011; Cong et al. 2012), and MODIS (Potter et al. 2008), have been widely used to explore vegetation dynamics and their relationships with climate variables.

In this study, the SPOT-VGT products (Tarnavsky et al. 2008; Jarlan et al. 2008; Zhong et al. 2010) are used for NDVI analysis. A 10-day composite with 1-km spatial resolution is obtained from the website (http://free.vgt.vito.be), available from April 1998 to October 2010. The maximum value composite (MVC) is applied to suppress atmospheric effects on NDVI (Holben 1986; Piao et al. 2004). However, the residual atmospheric contamination may still exist in the MVC-processed time series of NDVI (Verhoef et al. 2005; Julien and Sobrino 2010; Samanta et al. 2011). Thus, the Harmonic Analysis of Time Series (HANTS) algorithm (Verhoef et al. 1996; Roerink et al. 2003) is used to remove cloud contamination and reconstruct vegetation indexes for a time series of 453 SPOT-VGT scenes between April 1998 and October 2010. HANTS is an improved algorithm of the 
Fig. 1 Location map of Eastern China and three subregions ( 1 region I, 2 region II, 3 region III) described in the text. Circles denote selected 357

meteorological stations used in this study. The shade in the bottom-right figure is the study area, i.e., Eastern China

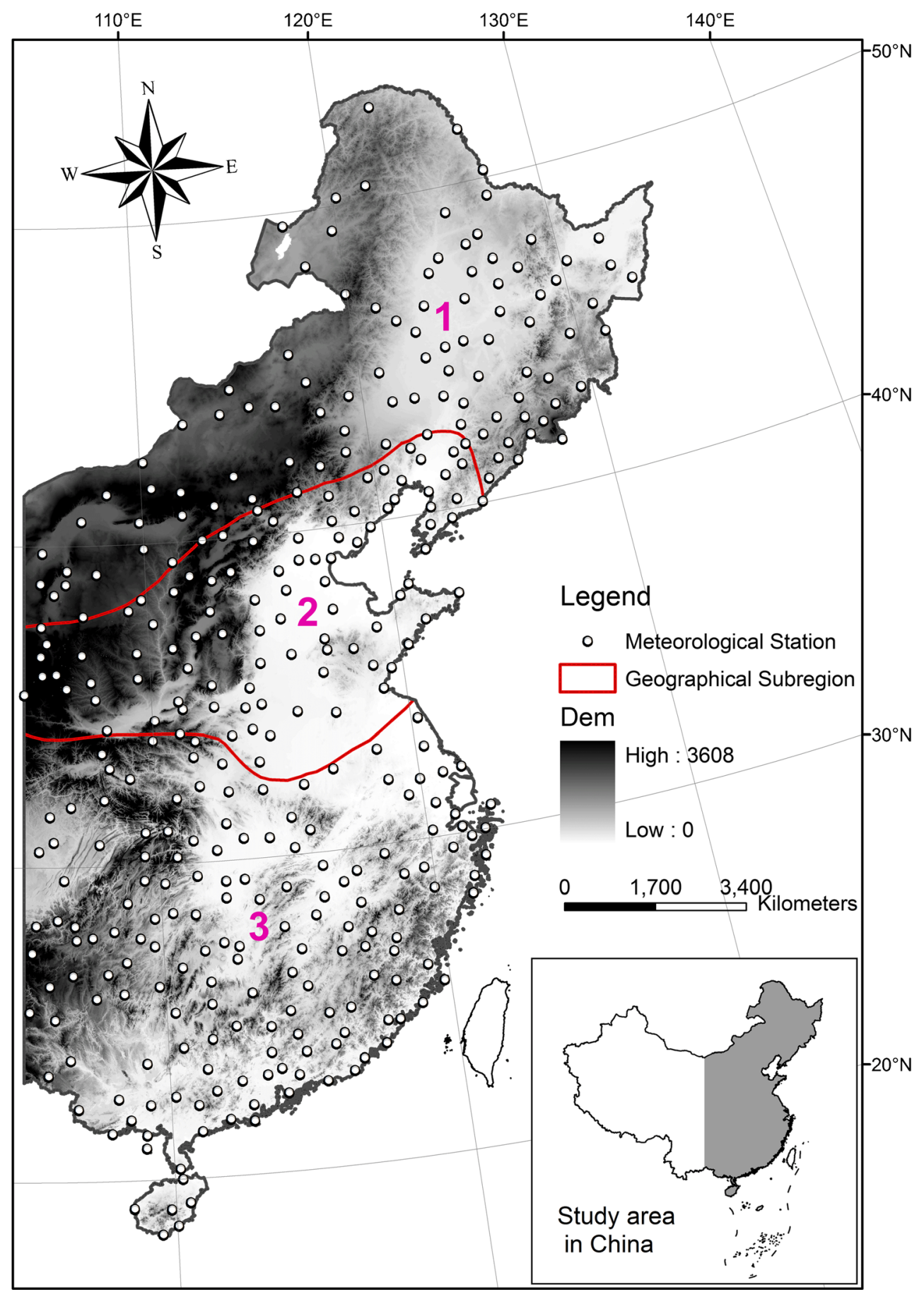

fast Fourier transform (Zhong et al. 2010; Cong et al. 2012). In HANTS, pronounced outliers are removed by assigning a weighting function of zero, changing the original curvefitting problem into a weighted least squares curve fitting process. The smooth curve is obtained by means of an average value plus a short series of harmonic (cosine) functions, each of which is defined by its amplitude and phase (for more description about HANTS algorithm, referring to Verhoef et al. 2005; Roerink et al. 2000; Julien and Sobrino 2010;
Zhong et al. 2010). In order to reduce the impacts of bare and sparsely vegetated regions on NDVI analysis, only grid cells with annual mean NDVI greater than 0.1 during the 13 -year period are considered (Zhou et al. 2001; Piao et al. 2006) in this study.

Daily precipitation data for the period 1961-2010 are available from 512 meteorological stations. These data are obtained from the National Climate Center of China, China Meteorological Administration. Data quality control is 
Fig. 2 Vegetation map of Eastern China (resolution 1:4,000,000, sources: Data Center for Resources and Environmental Sciences, Chinese Academy of Sciences)

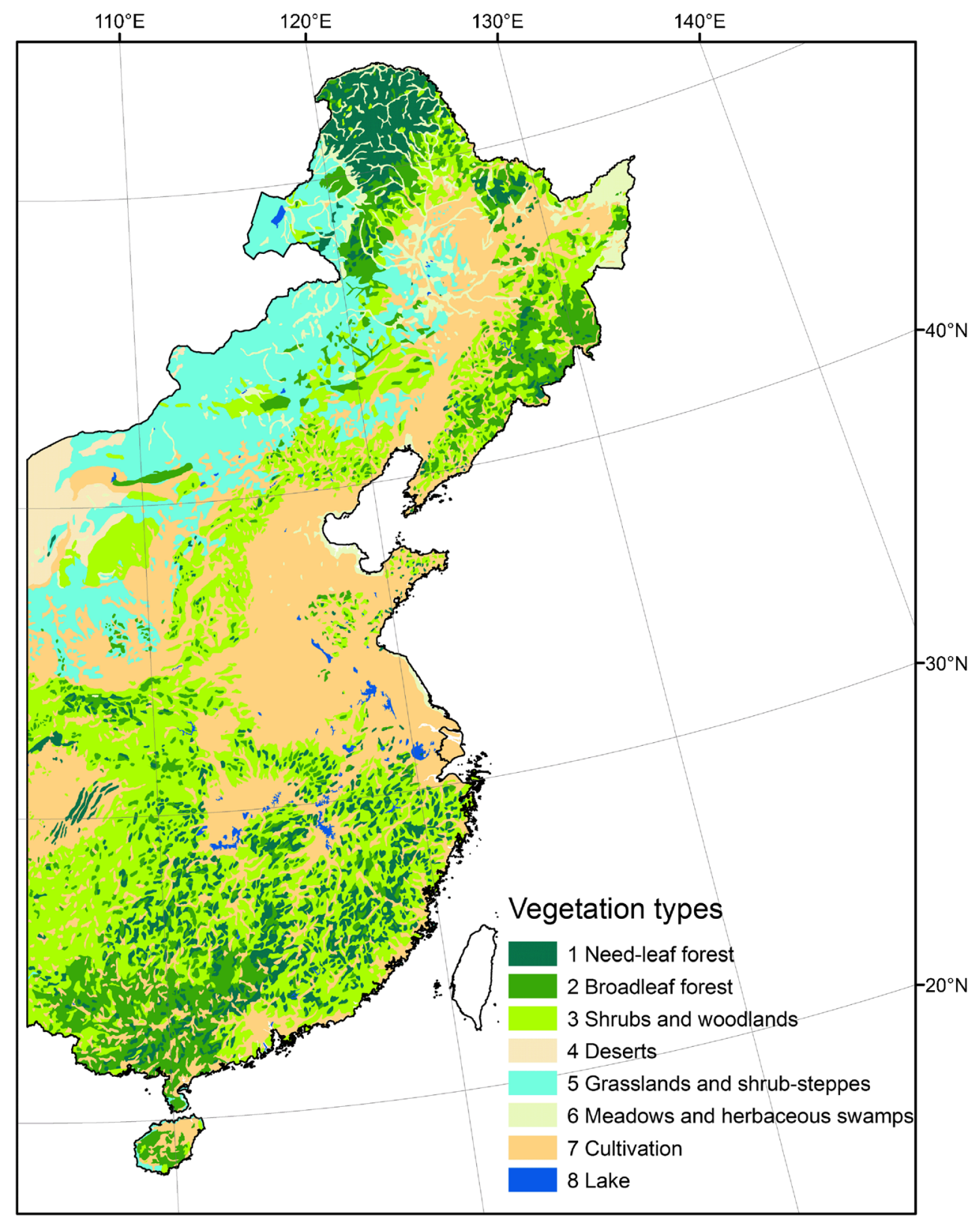

performed to remove errors from the observation data set, such as missing data and negative daily precipitation values (Jiang et al. 2011). The homogeneity of precipitation data series for each station is assessed using the RHtests dlyPrcp software package available from the website of the joint Meteorological Organization CCL/CLIVAR/JCOMM Expert Team on Climate Change Detection and Indices (ETCCDI) (http://cccma.seos.uvic.ca/ETCCDI) (Wang et al. 2010). In order to minimize the effects of inhomogeneity, the shortness of record length, and missing data, 357 meteorological stations are selected for this study (Fig. 1). Four precipitation indices (Table 1) are constructed based on the indicators recommended by ETCCDI. First, total precipitation amount (PRETOT) during the growing season or in each month of the
Table 1 Definitions of four precipitation indices

\begin{tabular}{|c|c|c|c|}
\hline No. & Index & Definition & Unit \\
\hline 1 & PRETOT & $\begin{array}{l}\text { Total rainfall amount for the month } \\
\text { or growing season }\end{array}$ & $\mathrm{mm}$ \\
\hline 2 & RD95p & $\begin{array}{l}\text { Number of days with daily rainfall } \\
\text { amount greater than or equal to } \\
\text { the 1961-1990 mean 95th percentile }\end{array}$ & days \\
\hline 3 & EPRETOT & $\begin{array}{l}\text { Total rainfall amount from precipitation } \\
\text { events greater than or equal to the } \\
\text { 1961-1990 mean 95th percentile } \\
\text { for the month or growing season }\end{array}$ & $\mathrm{mm}$ \\
\hline 4 & RINTEN & $\begin{array}{l}\text { Average intensity of precipitation events } \\
\text { greater than or equal to the 1961-1990 } \\
\text { mean 95th percentile }\end{array}$ & $\mathrm{mm} /$ day \\
\hline
\end{tabular}


growing season is summed. Then, the extreme precipitation threshold for each station is determined as the 1961-1990 mean 95th percentile of daily rainfall amount. Finally, based on these precipitation thresholds, extreme precipitation indices of frequency (RD95p), amount (EPRETOT), and intensity (RINTEN) are calculated for each station. Their equations are listed as follows:

$$
\begin{aligned}
& \operatorname{PRETOT}_{j}=\sum_{i=1}^{I} \mathrm{DP}_{i j} \\
& P_{\mathrm{thr}}=\sum_{i=1}^{n} \mathrm{DP}_{95 \mathrm{th}} / n \\
& \operatorname{RD}_{5} \mathrm{p}_{j}=\sum_{i=1}^{I} \mathrm{WD}_{i j}, \text { where }\left\{\begin{array}{l}
\mathrm{WD}_{i j}=0, \text { if } \mathrm{DP}_{i j}<P_{\mathrm{thr}} \\
\mathrm{WD}_{i j}=1, \text { if } \mathrm{DP}_{i j} \geq P_{\mathrm{thr}}
\end{array}\right.
\end{aligned}
$$

EPRETOT $_{j}=\sum_{w=1}^{W} \mathrm{DP}_{w j}$, where $\mathrm{DP}_{w j} \geq P_{\text {thr }}$

$$
\operatorname{RINTEN}_{j}=\text { EPRETOT }_{j} /{\mathrm{RD} 95 p_{j}}_{j}
$$

where $\mathrm{DP}_{i j}$ is daily rainfall amount on day $i$ in period $j$, and $I$ is the count of days in period $j ; P_{\text {thr }}$ is the extreme precipitation threshold for each station, and $\mathrm{DP}_{95 \text { th }}$ is the 95th percentile of daily rainfall amount on the $n$th year; $\mathrm{WD}_{i j}$ is the statistic value about the occurrence of extreme precipitation events on day $i$ in period $j$, if daily rainfall amount is greater than or equal to $P_{\text {thr }}, \mathrm{WD}_{i j}=1$, if daily rainfall amount is less than $P_{\text {thr }}, \mathrm{WD}_{i j}=0$; and $\mathrm{DP}_{w j}$ is daily rainfall amount great than or equal to $P_{\text {thr }}$ on day $w$ in period $j$, and $W$ is the count of days with daily rainfall amount greater than or equal to $P_{\text {thr }}$ in period $j$.

To analyze the relationships between NDVI and precipitation, the Person correlation coefficients between NDVI and four precipitation indices during the growing season and in each month of the growing season are calculated. In order to describe the spatial characteristics of precipitation, the spatial interpolation method is applied for the spatial scale expansion of four precipitation indices during the growing season with the same resolution as NDVI data. Many techniques are available to interpolate precipitation data set. The inverse distance weighting (IDW) and Kriging method have been widely applied for the spatial predication of precipitation (Watkins et al. 2005; Szolgay et al. 2009; Hussain et al. 2010; Teegavarapu et al. 2012). We use the Kriging method because it can provide more accurate estimates of precipitation during the growing season than the IDW method. The regional monthly values of four precipitation indices are calculated as the arithmetical mean of meteorological stations. Considering the time lag in vegetation response to precipitation anomalies, the correlation coefficients between monthly NDVI and precipitation indices of the previous month are also examined in this study.

In order to better present the regional difference of NDVI in response to precipitation variation, the whole study area is divided into three geographical subregions, including the mid-temperate region (region I), the warm temperate region (region II), and the tropical and subtropical regions (region III) (Fig. 1). These three subregions are attained from and simplified by seven natural divisions across China based on climate and geomorphology conditions (Zhao 1983).
Fig. 3 Distribution of growing season NDVI for the period 1998-2010

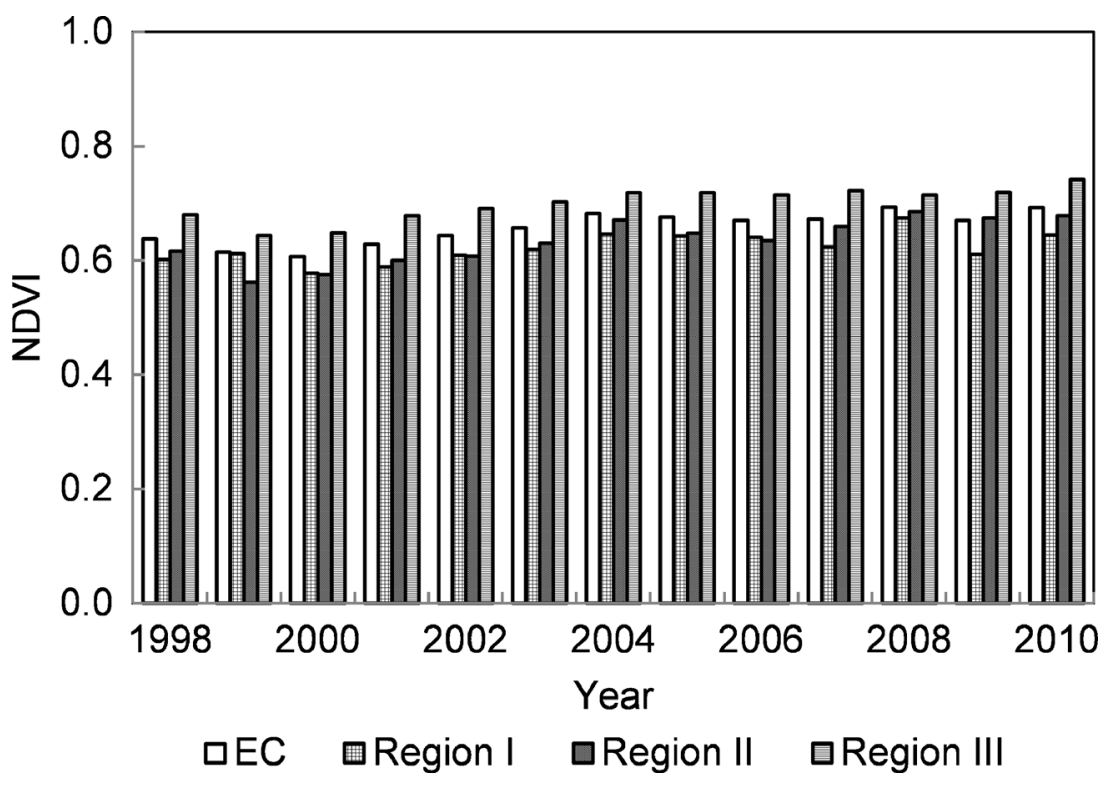




\section{Results and discussion}

\subsection{Interannual variability of NDVI}

The regional average of growing season NDVI in Eastern China for the period $1998-2010$ is 0.66 with a range from 0.61 to 0.69 and a variation coefficient of 0.04 , showing a low level of interannual variability. However, an obvious regional difference is observed (Fig. 3). Region III, with adequate rainfall and high temperature, has the largest NDVI values with an annual mean of 0.70 . In contrast, region I, with relatively low rainfall and temperature, has the lowest NDVI values with an annual mean of 0.62 .

In order to further demonstrate the spatial difference in NDVI, the distribution map of annual mean value is generated (Fig. 4). It shows that $75.4 \%$ of the total study area has NDVI values $>0.6$ while $16.6 \%$ of the total study area has NDVI values $>0.8$. The area with NDVI values $>0.8$ is mainly located in mountain areas of Northeastern China (i.e., Daxing'an Mountains, Xiaoxing'an Mountains, Changbai Mountains) (Fig. 4), where vegetation types are mostly dominated by forests or shrubs and woodlands (Fig. 2). On the contrary, about $2.9 \%$ of the total study area, located mainly in the northwestern part of Eastern China, retains very low NDVI values $(<0.2)$ (Fig. 4) because of the unique vegetation types such as deserts, grasslands, and shrub-steppes (Fig. 2).

From April to October, the regional average monthly NDVI in Eastern China is low in April (0.37) and reaches the maximum in August (0.64) (Fig. 5). Similar seasonal variations and intra-annual variability also exist for each subregion.
Fig. 4 The spatial distribution of annual mean values of growing season NDVI in Eastern China

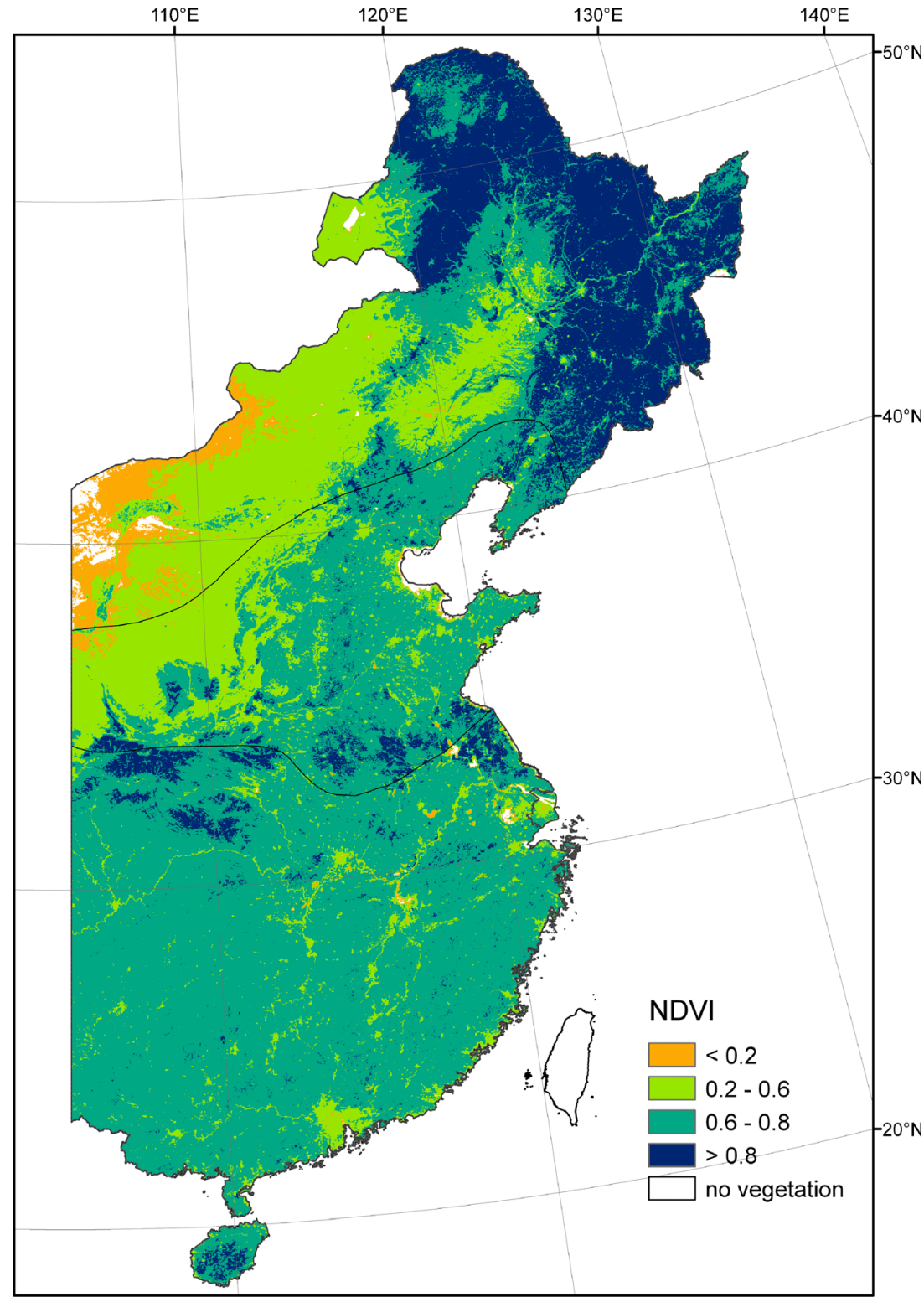


Fig. 5 The regional monthly NDVI variation averaged from 1998 to 2010 in Eastern China and three subregions

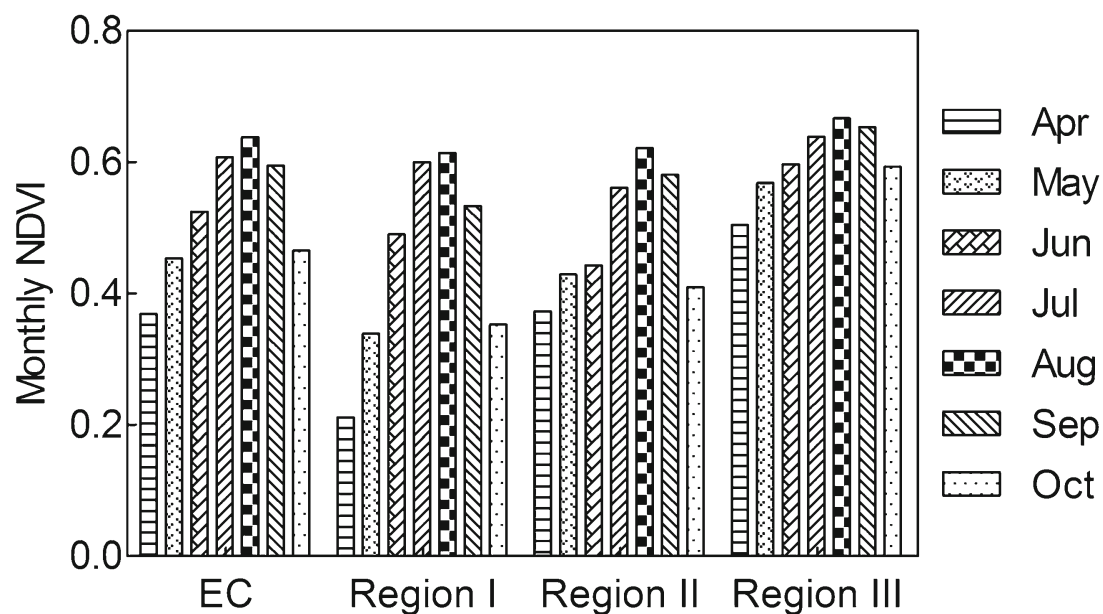

varies from 634.8 to $799.7 \mathrm{~mm}$ with an annual average of $700.6 \mathrm{~mm}$ and a variation coefficient of 0.08 (Fig. 6a), displaying a low annual variability for this period. However, the significant spatial variability in precipitation is observed.
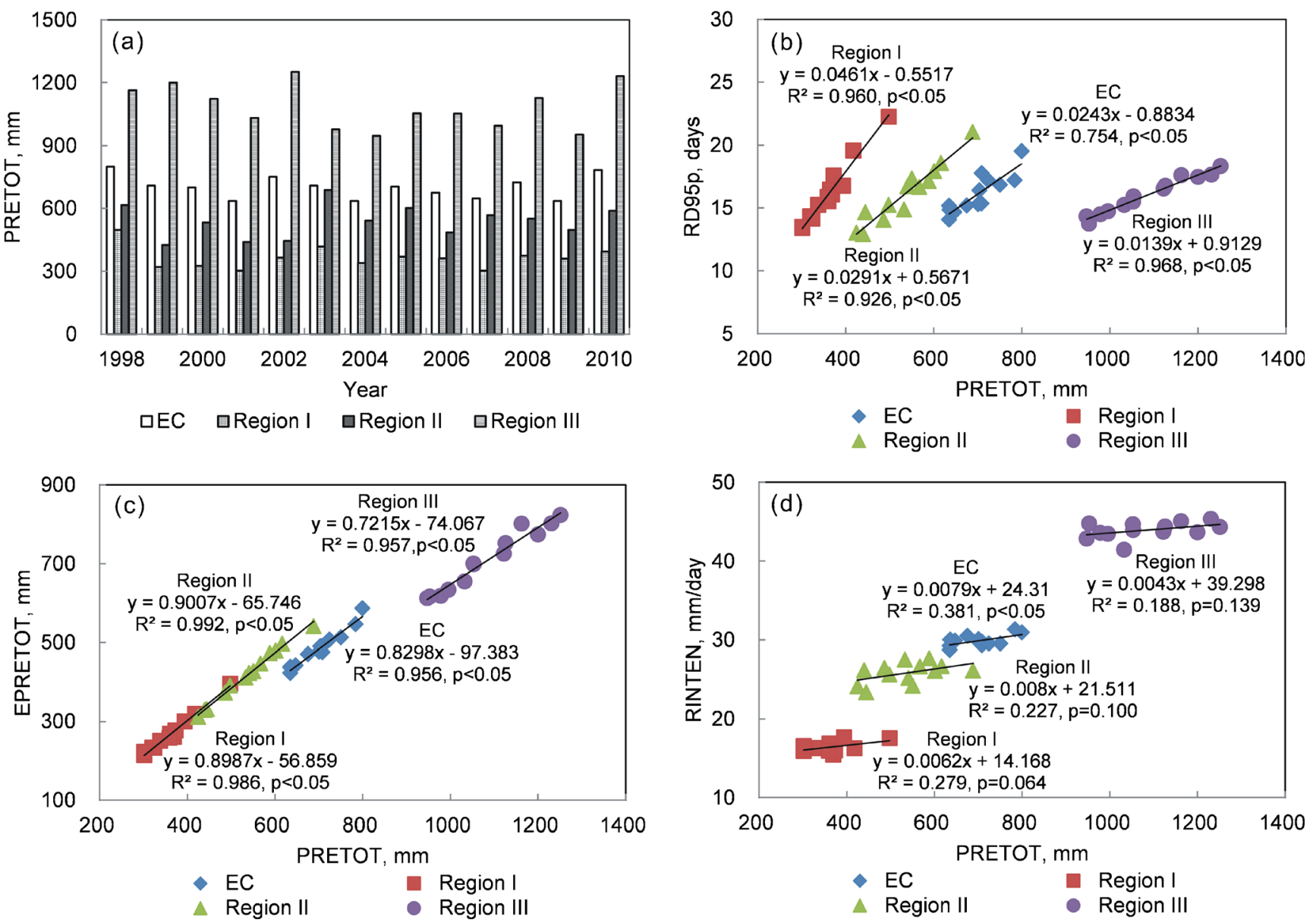

Fig. 6 Distribution of growing season PRETOT for the period 19982010 (a) and its correlations with growing season RD95p (b), EPRETOT (c), and RINTEN (d). The formulas $(\mathbf{b}, \mathbf{c}, \mathbf{d})$ are linear regression equations, $y$ is the value of extreme precipitation index, $x$ is the value of PRETOT, $R^{2}$ is the determination coefficient, and $p$ is the significance level

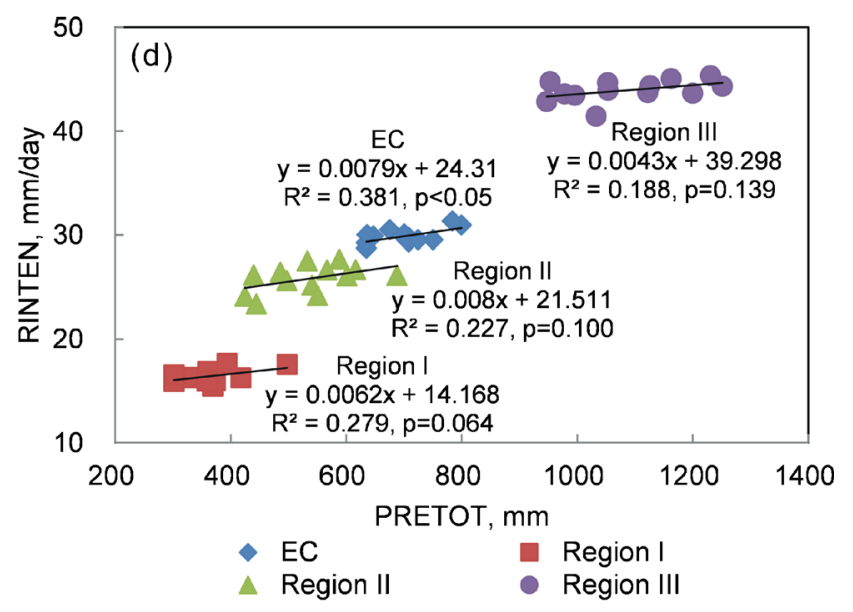


For example, region III has an annual mean of $1,085.2 \mathrm{~mm}$ (Fig. 6a) with very high precipitation occurring in Southeastern China ( $>1,200 \mathrm{~mm} / \mathrm{year}$ ) (Fig. 7a). In contrast, region I has an annual mean of only $363.3 \mathrm{~mm}$ (Fig. 6a) with very low precipitation in the northwestern part of Eastern China ( $<200 \mathrm{~mm} /$ year) (Fig. 7a).

Figure $6 b, c$ indicates that the growing season RD95p and EPRETOT have a strong correlation with growing season PRETOT in all subregions $(r=0.9)$. Moreover, the ratio of EPRETOT to PRETOT during the growing season is very high with an annual average of about 0.7. These findings suggest that PRETOT is mainly derived from EPRETOT. In other words, the extreme precipitation events can dominate the rainfall excess or deficiency of the study area, especially for region I and region II. Note that there is a small spatial variation in growing season RD95p (Fig. 7b), averaging 16 days/year.

RINTEN has a similar pattern of regional difference to PRETOT (Fig. 7d). However, its correlation with PRETOT is weaker than that of EPRETOT and RD95p with PRETOT (Fig. 6d), indicating that extreme precipitation events have a larger contribution to PRETOT and EPRETOT than to RINTEN during the growing season.

Influenced by the East Asia Summer Monsoon, regional mean monthly PRETOT, RD95p, and EPRETOT (averaged from 1998 to 2010) peak in July for the entire study area and regions I and II (Fig. 8a-c). However, these indices peak in June for region III because of the "Plum Rain Season" (known
Fig. 7 The spatial distribution of annual mean values of growing season PRETOT (a), RD95p (b), EPRETOT (c), and RINTEN (d) in Eastern China
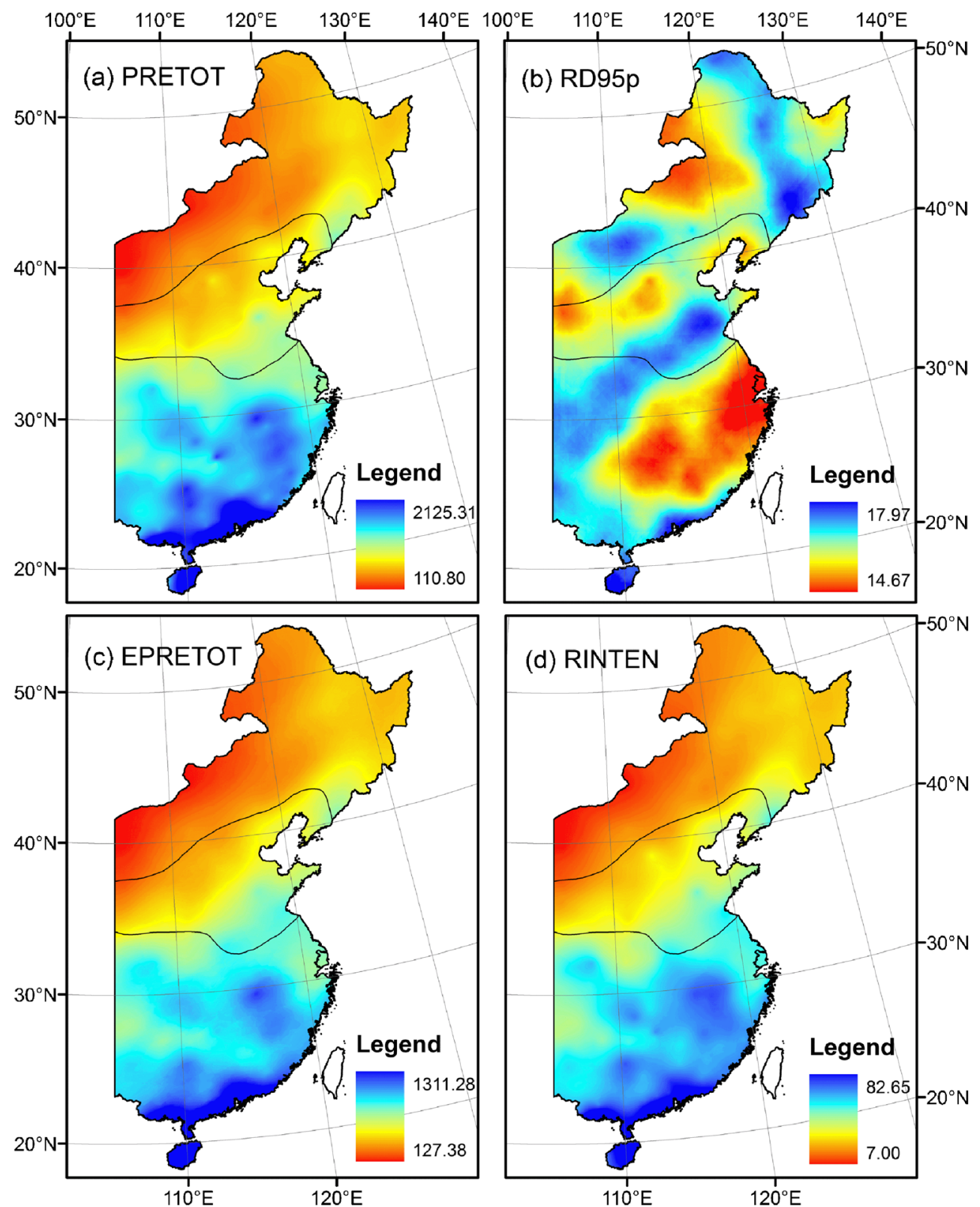

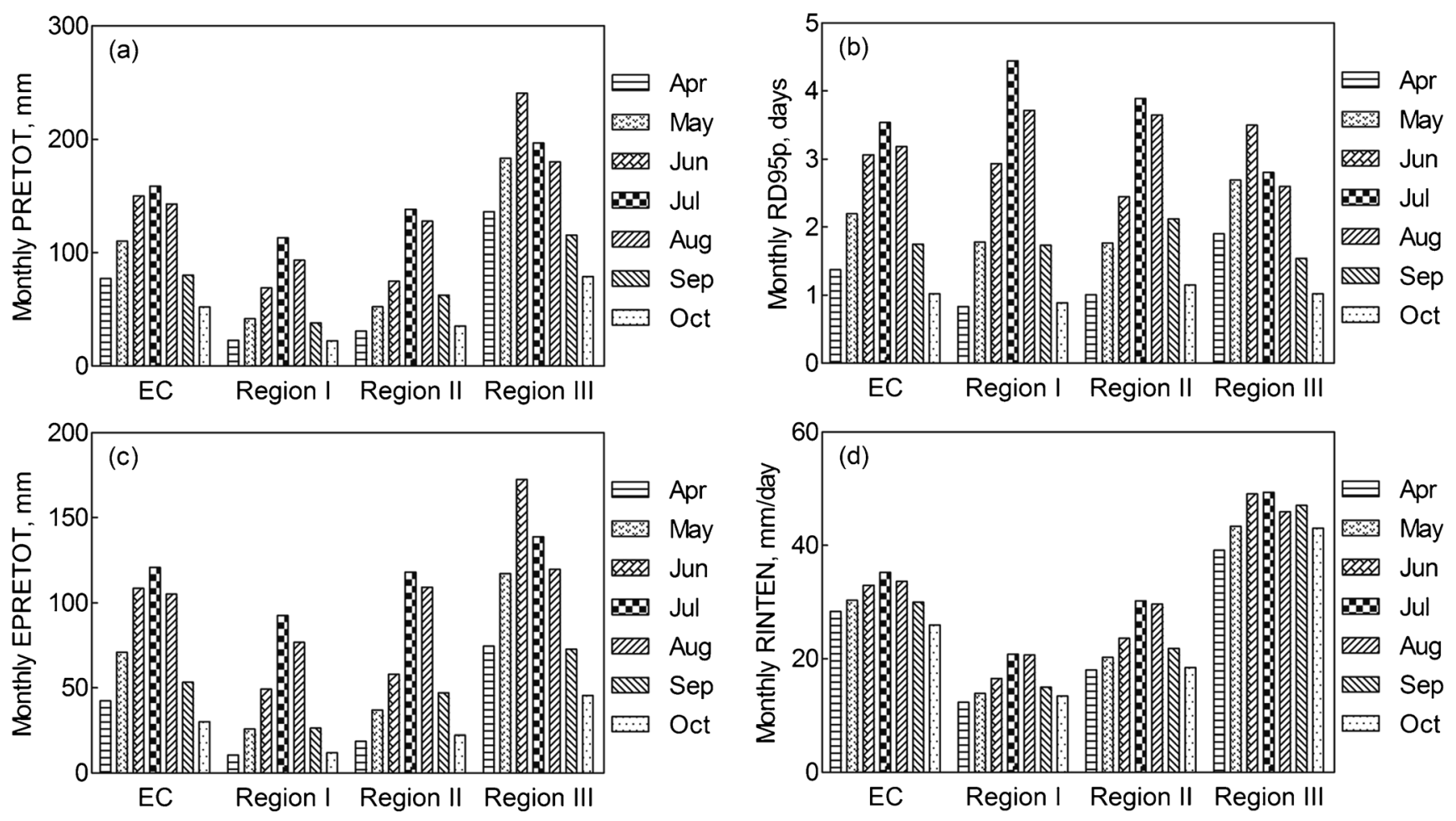

Fig. 8 The regional monthly precipitation variation averaged from 1998 to 2010 in Eastern China and three subregions

as Meiyu Season in China), which occurs from mid-June to early July. For Eastern China as a whole, peak values of monthly PRETOT, RD95p, and EPRETOT are $158.6 \mathrm{~mm}$, 3.5 days, and $120.7 \mathrm{~mm}$, respectively. They are 3.0, 3.5, and 4.0 times of their lowest monthly counterparts, exhibiting a large intra-annual variation. In contrast, there is a similar but relatively small seasonal difference in regional average monthly RINTEN (Fig. 8d).

Regional average monthly PRETOT (from April to October) is highly correlated with RD95p and EPRETOT with $r>0.9$ for all months and all subregions, further indicating that PRETOT is strongly associated with precipitation extremes in Eastern China. However, monthly RINTEN has a relatively low correlation with monthly PRETOT.

\subsection{Correlations between NDVI and precipitation}

\subsubsection{Correlations between growing season NDVI and precipitation}

The correlations between growing season NDVI and four precipitation indices indicate a large regional difference (Fig. 9). A significant positive correlation between growing season NDVI and PRETOT exists mainly in Northern China (Fig. 9a). These areas, accounting for $11.7 \%$ of the total study area, are largely in the arid to subhumid climate zones. The vegetation covers are mainly grasslands and shrub-steppes or shrubs and woodlands. Plant growth is greatly sensitive to precipitation anomalies. In contrast, growing season NDVI is negatively correlated with growing season PRETOT in $4.8 \%$ of the study area, mostly located in areas around the Yangtze River, the middle reaches of Pearl River and deep Northeastern China (Fig. 9a). In these humid areas, precipitation increment can increase cloud cover or cause floods, which can negatively impact plant growth or even damage vegetation cover. In addition, temperature is probably the limiting factor for plant growth in deep Northeastern China (Piao et al. 2006).

No obvious correlation is observed in the other regions (Fig. 9a), suggesting that vegetation dynamics may be affected by other factors. Figures 2 and 9a indicate that in most regions that are occupied by cultivation lands, vegetation seems to be not associated with precipitation, probably due to good irrigation management. In many areas of the Losses Plateau (Li et al. 2012) where land covers are mainly grasslands and shrubsteppes or shrubs and woodlands, NDVI variation may be influenced by soil and water conservation practices of afforestation and grassing. In most regions of Southern China and deep Northeastern China where the growing season NDVI is not correlated with PRETOT, adequate soil moisture could reduce the dependence of plants on precipitation conditions. In addition, temperature and radiation also influence NDVI variation and vegetation dynamics (Nemani et al. 2003; Piao et al. 2004). Piao et al. (2004) noted that NDVI is positively correlated with temperature in many areas of China, especially in the middle and lower reaches of Yangtze River, South China, 
Fig. 9 Correlation coefficients between growing season (AprilOctober) NDVI and four precipitation indices of PRETOT (a), RD95p (b), EPRETOT (c), and RINTEN (d) during 19982010 (the absolute value of 0.54 indicates significance at the 0.05 level)
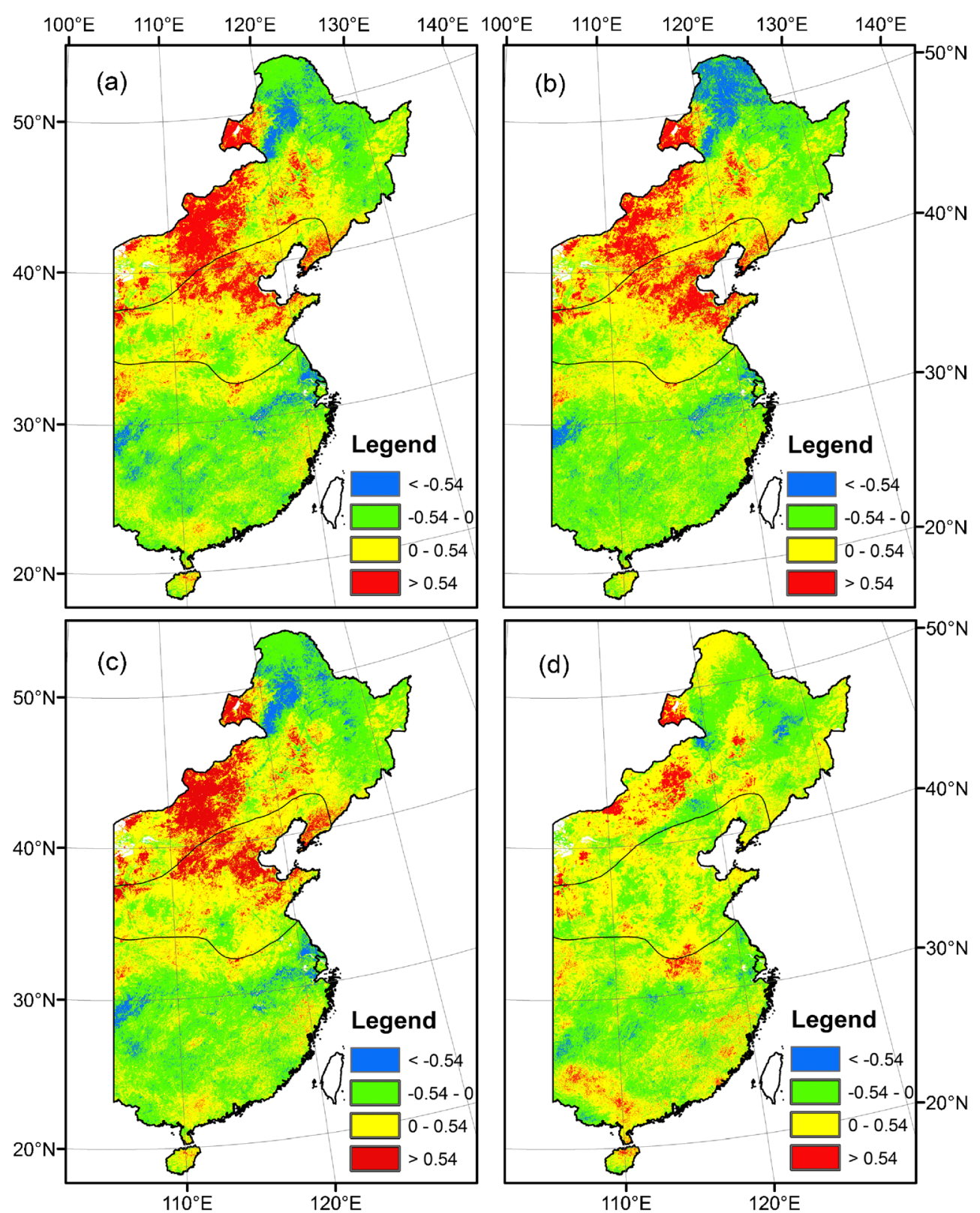

Daxing'an Mountains, and the middle reaches of Yellow River. Nemani et al. (2003) reported that vegetation cover is sensitive to radiation over south-central China.

Correlations between growing season NDVI and two of the extreme precipitation indices (RD95p and EPRETOT) have similar spatial patterns to that between NDVI and PRETOT (Fig. 9a-c). A significant positive correlation between growing season NDVI and RD95p exists in a larger area of CircumBohai-Sea region. Because this region is one of the places where the shortage of water resource is most severe in China (Jiang et al. 2011), extreme precipitation events can boost plant growth and increase the maximum value of NDVI. In contrast, correlations between growing season NDVI and RINTEN differ from that between growing season NDVI and
PRETOT. A significant positive correlation between growing season NDVI and RINTEN exists only in a smaller area, accounting for $4.4 \%$ of the study area (Fig. 9d). This is perhaps because in Northern China, rainfall is relatively low and PRETOT is more important to plant growth than RINTEN.

\subsubsection{Correlations between monthly NDVI and precipitation}

Tables 2 and 3 present the correlation coefficients between regional average monthly NDVI and two precipitation indices: PRETOT and RINTEN, respectively. The correlations between regional average monthly NDVI and other two precipitation indices (RD95p and EPRETOT) are not analyzed because NDVI response to RD95p and EPRETOT is similar 
Table 2 Correlation coefficients between regional average monthly NDVI and PRETOT from April to October (the absolute value of 0.54 corresponds to the 0.05 significant level)

\begin{tabular}{llrrrrrrr}
\hline Region & PRETOT & \multicolumn{1}{c}{ April } & \multicolumn{1}{c}{ May } & \multicolumn{1}{c}{ June } & \multicolumn{1}{c}{ July } & August & September & October \\
\hline EC & PRETOTm & -0.474 & 0.184 & -0.243 & 0.095 & -0.305 & $\mathbf{0 . 5 7 3}$ & -0.372 \\
\multirow{2}{*}{ Region I } & PRETOTm-1 & 0.187 & -0.198 & 0.141 & -0.076 & 0.176 & -0.225 & $\mathbf{0 . 6 4 2}$ \\
& PRETOTm & 0.186 & 0.516 & -0.174 & 0.025 & -0.194 & 0.443 & -0.334 \\
\multirow{2}{*}{ Region II } & PRETOTm-1 & -0.094 & 0.239 & $\mathbf{0 . 8 0 6}$ & -0.005 & 0.071 & 0.035 & $\mathbf{0 . 5 9 5}$ \\
& PRETOTm & 0.083 & $\mathbf{0 . 6 9 0}$ & -0.168 & 0.416 & 0.437 & $\mathbf{0 . 5 4 3}$ & -0.188 \\
\multirow{2}{*}{ Region III } & PRETOTm-1 & 0.083 & 0.501 & 0.529 & 0.099 & 0.535 & 0.443 & $\mathbf{0 . 6 2 0}$ \\
& PRETOTm & -0.507 & -0.201 & -0.496 & -0.135 & -0.524 & $\mathbf{0 . 6 0 3}$ & -0.201 \\
& PRETOTm-1 & -0.052 & -0.433 & -0.204 & -0.284 & -0.004 & -0.466 & $\mathbf{0 . 6 9 2}$ \\
\hline
\end{tabular}

Bold numbers indicate $p<0.05$

PRETOTm correlation coefficient between regional average monthly NDVI and PRETOT of current month, PRETOTm-1 correlation coefficient between regional average monthly NDVI and PRETOT of previous month

to PRETOT. Also included in Tables 2 and 3 are results of correlations of monthly NDVI against PRETOT and RINTEN of the previous month to examine the lag effect.

Table 2 shows that May NDVI is positively correlated to PRETOT of current month in region II and June NDVI is positively correlated with PRETOT of previous month in region I. In these regions, scarce rainfall in spring commonly limits the growth of vegetation such as forests, grasses, and agricultural crops. Increase in May precipitation can effectively improve soil moisture and promote plant growth of the current or following month. In addition, September NDVI has a positive correlation with PRETOT of current month in the whole study area, region II and region III. Moreover, we also find that October NDVI is strongly associated with PRETOT of previous month in the whole study area and all subregions. Because autumn rainfall is relatively low, increasing precipitation in September can enhance plant growth or prevent vegetation from early withering. A 1-month temporal lag between vegetation response and precipitation variation has also been reported by many previous studies (e.g., Weiss et al. 2004; Nezlin et al. 2005; Piao et al. 2006; Fabricante et al. 2009; Méndez-Barroso et al. 2009; Cui and Shi 2010; Zhong et al. 2010).

Similar to growing season results, monthly NDVI is less associated with monthly RINTEN than with monthly PRETOT. No obvious correlation is found between September or October NDVI and September RINTEN (Table 3). On contrary, there is a negative correlation between May NDVI and April RINTEN in region III, displaying an inverse response of vegetation to precipitation anomalies. This is possibly because in humid areas (region III), high precipitation intensity may reduce incoming solar radiation and restrain plant growth, thereby causing a decrease in NDVI values. In addition, monthly NDVI in May (for region II) and June (for regions I and II) is positively correlated with RINTEN of previous month, again showing that high precipitation in spring can advance plant growth in these regions.

Table 3 Correlation coefficients between regional average monthly NDVI and RINTEN from April to October (the absolute value of 0.54 corresponds to the 0.05 significant level)

\begin{tabular}{|c|c|c|c|c|c|c|c|c|}
\hline Region & RINTEN & April & May & June & July & August & September & October \\
\hline \multirow[t]{2}{*}{$\mathrm{EC}$} & RINTENm & -0.149 & -0.263 & 0.198 & -0.007 & -0.155 & 0.054 & -0.336 \\
\hline & RINTENm-1 & -0.062 & -0.128 & -0.304 & 0.102 & -0.042 & -0.223 & 0.066 \\
\hline \multirow[t]{2}{*}{ Region I } & RINTENm & 0.243 & 0.483 & 0.184 & -0.212 & 0.203 & 0.075 & 0.060 \\
\hline & RINTENm-1 & -0.472 & -0.049 & 0.706 & 0.323 & -0.317 & 0.136 & 0.489 \\
\hline \multirow[t]{2}{*}{ Region II } & RINTENm & 0.253 & 0.708 & -0.118 & -0.034 & 0.024 & -0.040 & 0.026 \\
\hline & RINTENm-1 & 0.185 & 0.569 & 0.586 & -0.009 & 0.048 & 0.050 & 0.040 \\
\hline \multirow[t]{2}{*}{ Region III } & RINTENm & -0.510 & 0.021 & -0.409 & 0.257 & -0.086 & 0.067 & 0.497 \\
\hline & RINTENm-1 & -0.023 & -0.561 & 0.022 & -0.136 & 0.263 & -0.209 & 0.134 \\
\hline
\end{tabular}

Bold numbers indicate $p<0.05$

RINTENm correlation coefficient between regional average monthly NDVI and RINTEN of current month, RINTENm- 1 correlation coefficient between regional average monthly NDVI and RINTEN of previous month 


\subsection{Comparison with other similar studies}

The relationships between vegetation cover and precipitation in Eastern China or the whole China have been reported in other studies (e.g., Piao et al. 2004; Yu et al. 2006; Weng and Zhou 2006; Wang et al. 2009; Cui and Shi 2010; Meng et al. 2011). Our findings support many of the early results. For instance, Cui and Shi (2010) noted that the maximum response of NDVI to precipitation variation is more pronounced in Northern China than Southern China. This is consistent with our study. We detect that the mid-western part of region I has the strongest correlations between growing season NDVI and precipitation and so did Piao et al. (2004), Yu et al. (2006), as well as Weng and Zhou (2006). However, different findings also exist between our study and the earlier ones, partly due to different study periods, studying methods, spatial domains, and adopted remote sensing data. For example, we find that Circum-Bohai-Sea region has a larger area showing significant positive correlations between growing season NDVI and precipitation than Piao et al. (2004).

In spite of many similar studies, correlations between NDVI and precipitation extremes are rather scarcely assessed in the literature. Our study indicated that in some regions (e.g., Circum-Bohai-Sea region), extreme precipitation frequency (RD95p) has greater influences on vegetation dynamics than precipitation amount (PRETOT). For the entire Eastern China, extreme precipitation intensity (RINTEN) has a weaker correlation with NDVI. The results are helpful for the development of appropriate adaptation and mitigation strategies to cope with precipitation anomalies for agriculture development and ecosystem construction.

\section{Conclusions}

Based on the SPOT/VEGETATION NDVI data and daily precipitation data, the temporal variability and spatial pattern of NDVI and precipitation as well as their relationships are explored in Eastern China for the period 1998-2010. The results show a pronounced regional and seasonal difference for both variables (NDVI and precipitation) and their correlations.

In spite of a low interannual variability, but NDVI displays a notable intra-annual variation. Spatially, $16.6 \%$ of the study area has a very high value of growing season NDVI $(>0.8)$ while about $2.9 \%$ of the study area with a very low value $(<0.2)$. Similarly, precipitation amount (PRETOT) also displays a low interannual but a large intra-annual variability from 1998 to 2010. Spatially, Southeastern China has a high value of growing season precipitation while low in the northwestern part of Eastern China. Extreme precipitation days (RD95p) and amount (EPRETOT) are well correlated with PRETOT while RINTEN has a similar regional difference to PRETOT but with a smaller seasonal variation than PRETOT.
NDVI shows the different strength of correlations with PRETOT, RD95p, EPRETOT, and RINTEN. In $11.7 \%$ of the study area, mainly located in Northern China, there is a positive correlation between growing season NDVI and PRETOT. In contrast, in $4.8 \%$ of the study area, mostly located in areas around the Yangtze River, the middle reaches of Pearl River and deep Northeastern China, growing season NDVI is negatively correlated with growing season PRETOT. On a monthly scale, NDVI exhibits a positive correlation with PRETOT in May (for region II) and September (all subregions except region I). In addition, a significant temporal lag of NDVI behind PRETOT by 1 month is observed in June (for region I) and October. The relationships between RD95p and EPRETOT have a similar pattern to PRETOT, but in CircumBohai-Sea region, there is a larger area presenting a positive correlation between growing season NDVI and RD95p. In contrast, the correlations between NDVI and RINTEN are weaker during the growing season and its months.

In summary, this study gains a general knowledge of interannual variability of vegetation cover and precipitation (and its extremes) as well as their correlations in Eastern China for the period 1998-2010. Interestingly, our findings also suggest that vegetation response to precipitation and its extremes is affected by many other factors, such as temperature, radiation, and human disturbance. It should be noted that China, especially Eastern China, has been experiencing rapid economic developments along with large-scale ecological construction programs for ecological protection and restoration. This will insert strong influences on vegetation. Thus, the effects of both climatic variables and human activities should be taken into account to interpret vegetation dynamics.

Acknowledgments This study is financially supported by the National Natural Science Foundation of China (no. 40901028) and the Key Research Program of the Chinese Academy of Sciences (no. KZZD-EW-14). The authors kindly thank the National Climate Center of the China Meteorological Administration and the Flemish Institute for Technological Research (VITO) for providing the data for this study. We wish to thank Dr. Xiaolan L. WANG and Miss Kejing Liu for their helps in the homogeneous tests of precipitation data series. We are very grateful to the anonymous reviewers for their helpful comments and suggestions. Mr. Yuandong Wang is acknowledged for his help in using the HANTS algorithm to remove the atmospheric contamination from NDVI time series.

\section{References}

Bates JD, Svejcar T, Miller RF, Angell RA (2006) The effects of precipitation timing on sagebrush steppe vegetation. J Arid Environ 64:670-697

Cong N, Piao SL, Chen AP, Wang XH, Lin X, Chen SP, Han SJ, Zhou GS, Zhang XP (2012) Spring vegetation green-up date in China inferred from SPOT NDVI data: a multiple model analysis. Agric For Meteorol 165:104-113

Cui LL, Shi J (2010) Temporal and spatial response of vegetation NDVI to temperature and precipitation in Eastern China. J Geogr Sci 20(2): $163-176$ 
Domroes M, Schaefer D (2008) Recent climate change affecting rainstorm occurrences: a case study in East China. Clim Past 4:303-309

Fabricante I, Oesterheld M, Paruelo JM (2009) Annual and seasonal variation of NDVI explained by current and previous precipitation across Northern Patagonia. J Arid Environ 73:745-753

García-Romero A, Muñoz J, Andrés N, Palacios D (2010) Relationship between climate change and vegetation distribution in the Mediterranean mountains: Manzanares Head valley, Sierra De Guadarrama (Central Spain). Clim Chang 100:645-666

Holben BN (1986) Characteristics of maximum value composite images from temporal AVHRR data. Int J Remote Sens 7:1417-1434

Hussain I, Spöck G, Pilz J, Yu HL (2010) Spatio-temporal interpolation of precipitation during monsoon periods in Pakistan. Adv Water Resour 33:880-886

Jarlan L, Mangiarotti S, Mougin E, Mazzega P, Hiernaux P, Dantec VL (2008) Assimilation of SPOT/VEGETATION NDVI data into a sahelian vegetation dynamics model. Remote Sens Environ 112: 1381-1394

Jiang DJ, Wang K, Li Z, Wang QX (2011) Variability of extreme summer precipitation over Circum-Bohai-Sea region during 1961-2008. Theor Appl Climatol 104:501-509

Jiang DJ, Fu XF, Wang K (2013) Vegetation dynamics and their response to freshwater inflow and climate variables in the Yellow River Delta, China. Quatern Int 304:75-84

Julien Y, Sobrino JA (2010) Comparison of cloud-reconstruction methods for time series of composite NDVI data. Remote Sens Environ 114:618-625

Kaufmann RK, Zhou L, Myneni RB, Tucker CJ, Slayback D, Shabanov NV (2003) The effect of vegetation on surface temperature: a statistical analysis of NDVI and climate data. Geophys Res Lett 30(22):2147. doi:10.1029/2003GL018251

Li Z, Zheng FL, Liu WZ (2012) Spatiotemporal characteristics of reference evapotranspiration during 1961-2009 and its projected changes during 2011-2099 on the Loess Plateau of China. Agric For Meteorol 154-155:147-155

Méndez-Barroso LA, Vivoni ER, Watts CJ, Rodríguez JC (2009) Seasonal and interannual relations between precipitation, surface soil moisture and vegetation dynamics in the North American monsoon region. J Hydrol 377:59-70

Meng M, Ni J, Zong MJ (2011) Impacts of changes in climate variability on regional vegetation in China: NDVI-based analysis from 1982 to 2000. Ecol Res 26:421-428

Nemani RR, Keeling CD, Hashimoto H (2003) Climate-driven increases in global terrestrial net primary production from 1982 to 1999 . Science 300:1560-1563

Nezlin NP, Kostianoy AG, Li BL (2005) Inter-annual variability and interaction of remote-sensed vegetation index and atmospheric precipitation in the Aral Sea region. J Arid Environ 62:677-700

Piao SL, Fang JY, Ji W, Guo QH, Ke JH, Tao S (2004) Variation in a satellite-based vegetation index in relation to climate in China. J Veg Sci 15:219-226

Piao SL, Mohammat A, Fang JY, Cai Q, Feng JM (2006) NDVI-based increase in growth of temperate grasslands and its responses to climate changes in China. Glob Environ Chang 16:340-348

Potter C, Boriah S, Steinbach M, Kumar V, Klooster S (2008) Terrestrial vegetation dynamics and global climate controls. Clim Dyn 31:6778

Qi J, Marsett RC, Moran MS, Goodrich DC, Heilman P, Kerr YH, Dedieu G, Chehbouni A, Zhang XX (2000) Spatial and temporal dynamics of vegetation in the San Pedro River basin area. Agric For Meteorol 105:55-68

Qiu HJ, Cao MM (2011) Spatial and temporal variations in vegetation cover in China based on SPOT vegetation data. Resour Sci 33(2): 335-340

Rees M, Condit R, Crawley M, Pacala S, Tilman D (2001) Long-term studies of vegetation dynamics. Science 293:650-655
Roerink GJ, Menenti M, Verhoef W (2000) Reconstructing cloudfree NDVI composites using Fourier analysis of time series. Int J Remote Sens 21(9):1911-1917

Roerink GJ, Menenti M, Soepboer W, Su Z (2003) Assessment of climate impact on vegetation dynamics by using remote sensing. Phys Chem Earth 28:103-109

Salim HA, Chen XL, Gong JY (2008) Analysis of Sudan vegetation dynamics using NOAA-AVHRR NDVI data from 1982-1993. J Asian Earth Sci 1:1-15

Samanta A, Costa MH, Nunes EL, Vieira SA, Xu L, Myneni RB (2011) Comment on drought-induced reduction in global terrestrial net primary production from 2000 through 2009. Science 333:1093

Suzuki R, Masuda K, Dye DG (2007) Interannual covariability between actual evapotranspiration and PAL and GIMMS NDVIs of Northern Asia. Remote Sens Environ 106:387-398

Szolgay J, Parajka J, Kohnová S, Hlavčová K (2009) Comparison of mapping approaches of design annual maximum daily precipitation. Atmos Res 92:289-307

Tarnavsky E, Garrigues S, Brown ME (2008) Multiscale geostatistical analysis of AVHRR, SPOT-VGT, and MODIS global NDVI products. Remote Sens Environ 112:535-549

Teegavarapu RSV, Meskele T, Pathak CS (2012) Geo-spatial grid-based transformations of precipitation estimates using spatial interpolation methods. Comput Geosci 40:28-39

Verhoef W, Menenti M, Azzali S (1996) A colour composite of NOAAAVHRRNDVI based on time series analysis (1981-1992). Int J Remote Sens 17(2):231-235

Verhoef W, Kamp A, Koelemeijer R (2005) Climate indicators from time series of NDVI images (CITISEN) report. National Aerospace Laboratory, NLR, the Netherlands

Wang YL, Fan GZ, Zhou DW, Hua W, Huang XL (2009) The study of the relationship between Normalized Difference Vegetation Index and both temperature and precipitation in east China. J Trop Meteorol 25(6):725-732

Wang XLL, Chen HF, Wu YH, Feng Y, Pu Q (2010) New techniques for the detection and adjustment of shifts in daily precipitation data series. J Appl Meteorol Climatol 49:2416-2436

Watkins DW Jr, Link GA, Johnson D (2005) Mapping regional precipitation intensity duration frequency estimates. J Am Water Res Assoc 41(1):157-170

Weiss JL, Gutzler DS, Allred Coonrod JE, Dahm CN (2004) Seasonal and inter-annual relationships between vegetation and climate in central New Mexico, USA. J Arid Environ 57:507-534

Weng ES, Zhou GS (2006) Modeling distribution changes of vegetation in China under future climate change. Environ Model Assess 11:45-58

Yu L, Cao MK, Li KR (2006) Climate-induced changes in the vegetation pattern of China in the 21st century. Ecol Res 21:912-919

Zhao SQ (1983) A new scheme for comprehensive physical regionalization in China. Acta Geogr Sinic 38(1):1-10

Zhong L, Ma YM, Salama SM, Su ZB (2010) Assessment of vegetation dynamics and their response to variations in precipitation and temperature in the Tibetan Plateau. Clim Chang 103:519-535

Zhou LM, Tucker CJ, Kaufmann RK, Slayback D, Shabanov NV, Myneni RB (2001) Variations in northern vegetation activity inferred from satellite data of vegetation index during 1981 to 1999. J Geophys Res Atmos 106(D17):20069-20083

Zhou D, Fan G, Huang R, Fang Z, Liu Y, Li H (2007) Interannual variability of the normalized difference vegetation index on the Tibetan Plateau and its relationship with climate change. Adv Atmos Sci 24(3):474-484

Zhu YL, Wang HJ, Zhou W, Ma JH (2011) Recent changes in the summer precipitation pattern in East China and the background circulation. Clim Dyn 36(7-8):1463-1473

Zuo ZY, Zhang RH, Zhao P (2011) The relation of vegetation over the Tibetan Plateau to rainfall in China during the boreal summer. Clim Dyn 36:1207-1219 